\title{
The Social Interaction of Millennials in Real Space Due To the Development of Information Technology
}

\author{
Dwi Sulistyawati ${ }^{1}$, Imam Santosa ${ }^{2}$ and Deddy Wahyudi \\ ${ }^{123}$ ISRD, Faculty of Art and Design Institut Teknologi Bandung, Indonesia \\ ${ }^{1}$ soeli1988@gmail.com, 2imamz@fsrd.itb.ac.id, deddywahyudi@yahoo.com
}

\begin{abstract}
Human ability to understand the space created to meet their needs, depends on how the interaction between humans and space, how the influence of space or the built environment on attitudes and behavior. The factor of understanding space with its behavior involves deeper matters concerning the behavioral aspects of the user, is how his perception of a space, how the needs of social interaction between users, and how the space understood is formed from the perception of certain senses; a period, period, or long period of time, and how space can be understood also not only as space but is a place that gives a certain sensation to the millennial generation.Communities that originally interacted in real and faceto-face spaces, in the era of information revolution through the internet media can now interact with anyone without limits of space, distance and time, and facilitate and pamper people in meeting their needs without having to interact directly (reality existence) it can change lifestyles that are reflected through the cultural character of community behavior in the Millennial generation that impacts the real space itself
\end{abstract}

Keywords: Millennial Generation Social Interaction, Space, Information Technology

\section{INTRODUCTION}

Millennials who are space users can experience changes in character and behavior, both the influence of internal and external factors that result in responses to their environment. One of the most influential factors is the presence of new technology as a new subsystem in modern society that will bring various consequences, other subsystems in the system. Information technology as a subsystem will change the patterns of individual daily activities. The presence of gadgets due to the Internet of Thing (IoT) with various Google applications, online shopping, social media, etc., will lead to the emergence of a new agenda as a change in the behavior of activities in space as a means of supporting their daily life. The Character and Behavior that is reflected through the lifestyle of the Millennials has an interesting spatial problem when real space is beginning to be replaced by virtual space. Therefore, space as a place for social interaction Social Space for Millennials has its own form and value

The development of information technology has created a 'new space' that is artificial and virtual, namely cyberspace. Cyberspace has transferred various human activities (political, 
social, economic, cultural, spiritual, sexual) in the 'real world' to various forms of artificial substitution, so that anything that can be done in the real world can now be done in an artificial form in cyberspace. A massive migration of human life seems to be taking place, namely the migration from the 'real universe' to the 'virtual universe', from life in 'real space' to life in 'virtual space'[1].

The amazing social fact is that users of this cyberspace facility penetrate all walks of life and touch all ages and social strata, especially generation of gadgets (millennials), from the center to the remote villages to the farthest reaches of satellites from their providers. Life activities spent on a high acceleration work cycle become a trap in the accelerating rhythm while narrowing the space and time for the journey of spiritual life. Achieving the peak of acceleration on the one hand increased efficiency, effectiveness and comfort, on the other hand is a trigger in narrowing the level of achievement of humanistic spirituality to share space and time to make small talk, reprimand greetings and social interaction. The concept of real presence shifts to space where the concept of imaginary presence becomes dominant as the excesses of the decline in the quality of social interaction and lose layers of humanist tolerance.

\section{METHOD}

This article using a qualitative approach whose researchers explore real-life, contemporary limited systems (cases) and a variety of limited systems (various cases) through the collection of detailed and in-depth data that involves diverse sources of information or multiple sources of information and report on case descriptions and case themes. This research uses a qualitative approach. Qualitative research is research based on the quality or the quality of the objectives of a study. In general, qualitative research is designed for a very broad object of study and does not use scientific methods as a benchmark. Research is said to use a qualitative approach, as the data needed is not in the form of numbers and analysis uses words without statistical formulas[2].

\section{RESULT AND DISCUSSION}

According to Lefebvre, space is always social space because space is a social product. To understand space as a social product, it is first important for us to get out of old habits and understanding in understanding space as imagined as a kind of independent material reality or understanding space as self (space in itself). Contrary to the view of space as self-sufficient, Lefevbre uses the concept of production of space, which contains an understanding of space which is fundamentally tied to social reality. For him understanding space as in itself, will never find an adequate epistemological starting point. He asserted that space never existed "like himself", he was socially produced. Before explaining how space becomes social space. Lefebvre divides two types of space namely: absolute space and abstract space.

For Lefevbre, space is vital for social interaction. In this case he also recognizes the importance of life experiences in time and in the social production of space. Regarding the relationship between space and time in that experience he stressed:"They live time, after all; they are in time. Yet all who sees is movements. In nature, time is apprehended within space in the very heart of space ".

The view of "time in and through space" is very important in understanding the social or "living space". Here Lefebvre focuses on how social space is produced. Social Space is not a "thing" but a set of relations between objects and material products. To explain space as a social product, Lefebvre proposes a triadic dimension of space that shows the spatial production, namely: 
First, spatial practice. This concept refers to the dimensions of various practices and activities and social relations. Spatial classification emphasizes aspects of simultaneous activity. In a concrete form, the spatial Practice contains various networks of interaction, communication and various processes of production and exchange in communities that grow in everyday life Second, the representation of space. Referring to the representation of space in various images and conceptualizations so that something is referred to as space. The representation of space refers to various attempts to verbalize the form of space: language, ideology. Lefebvre gives examples of maps, cartography, signs, information on drawings, mockups including various sciences relating to them such as architecture, urban planning and even social science and geography.

Third, representation space. This third dimension is called by Lefebvre as a reversal of the representation of space. Space Representation contains the symbolic dimensions of space. Space Representation establishes an element that does not refer to space itself but to something else outside of space; supernatural power, language, country, principles of masculinity and femininity etc. This dimension of space production is an imaginative dimension that connects space with symbols and meanings such as monuments, artifacts, monumentsIn Spatial Practices, social space appears as a chain that connects various networks of activity in which there is also a material dimension of that interaction. In Spatial Representation, linguistic practices are defined linguistically and get demarcation as space. Representation here functions as an organizing scheme or framework for communication and orientation that enables social interaction. In the Representation Room there are various complex experiences.

Based on the three dimensions of social production, Lefebvre formulates three characters of space as social products:

(1) Perceived space: each space has a perceptive aspect in the sense that it can be accessed by the five senses so as to enable social practice. This is the material element that substitutes space.

(2) Conceived space: space cannot be perceived without being understood or accepted in the mind. An understanding of space is always also a production of knowledge.

(3) Lived space: the third dimension of space production is the experience of life. This dimension refers to the world as experienced by humans in the practice of daily life. According to him, human life and experience cannot be fully explained by theoretical analysis. There is always a surplus, residue or residue that escapes language or concepts, and often can only be expressed through artistic forms

\subsection{The Millennial Generation's Social Interaction affects Space}

Interaction is an interpersonal exchange where each person shows their behavior in one another in their presence and each behavior influences one another. Thibaut and Kelley put forward the notion of interaction, Interaction is an event affecting each other when two or more people are present together, which then they create an outcome with each other or communicate with each other. Thus, everyone's actions aimed at influencing other individuals occur in each case of interaction. According to Chaplin, Understanding Interaction is a social relationship between several individuals that are natural in nature that individuals influence each other at the same time.

Interaction is an interpersonal exchange where each person shows their behavior in one another in their presence and each behavior influences one another. Thibaut and Kelley put forward the notion of interaction, Interaction is an event affecting each other when two or more people are present together, which then they create an outcome with each other or 
communicate with each other. Thus, everyone's actions aimed at influencing other individuals occur in each case of interaction. According to Chaplin, Understanding Interaction is a social relationship between several individuals that are natural in nature that individuals influence each other at the same time.

From the understanding of the interaction above, it can be concluded that the interaction is a reciprocal relationship between two or more people and each person involved in it plays an active role. In the process of interaction not only occurs the relationship between the parties involved, but also influences one another. In every interaction always implies interpersonal communication, and vice versa, every interpersonal communication always contains interaction in it. It is difficult to separate between the two. On this basis, the forms of interaction according to Shaw as follows:

(1) Verbal interaction is one form of interaction that occurs when two or more people make contact with each other by using articulation tools. The process takes place in the form of conversations with each other.

(2) Physical interaction is a form of interaction that occurs if there are two or more people who make contact using body language. Examples of these interactions: body position, facial expressions, body movements and eye contact.

(3)Emotional interaction is a form of interaction that occurs when individuals make contact with one another by pouring out feelings. An example of this interaction: shedding tears as a sign of being sad, emotional or even too happy

In addition to the three types of interactions above, Nicholas distinguishes forms of interaction based on the number of individuals involved in the process and the patterns of interaction that occur. The forms of interaction are:

(1)Dyadic interaction is one form of interaction that occurs if there are two people involved in it or more than two people but the direction of interaction occurs only in two directions

(2) Tryadic interaction is a form of interaction that occurs if the individuals involved in it are more than two people and the pattern of interaction spreads to all individuals involved.

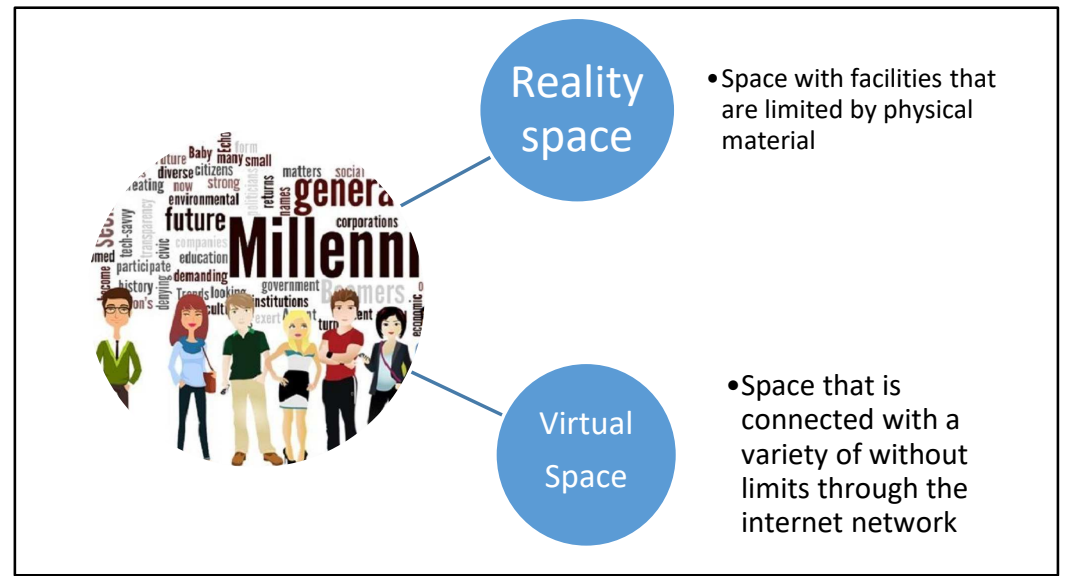

Figur 1: Space for Social Interaction 


\subsection{The Millennial Generation in Utilizing InformationTechnology}

The information technology revolution can have asocial impacts and and or radical changes in technical efficiency, easily convinced that these impacts are such that they produce an entirely new form of society. (Information society)

Bell distinguishes the conceptually terms as follows: information means 'data processing in a broad sense'; knowledge means 'an organized set of statements of facts or ideas, presenting reasonable judgments or experimental results, which are sent to others through several communication media in some systematic form' [3]. In practice he often uses the two terms interchangeably when discussing post-industrial society, although often, as we will see, his theory depends on the specific meaning of the term 'knowledge'. 2 John Goldthorpe complained in 1971 of 'the reappearance of historicalism' among social scientists, and he accused Bell directly, 'although historical arguments may not be openly presented or may be totally rejected' . 3 'When national income increases, one discovers, as in the Christian Engel theorem. . . that the proportion of money devoted to food at home begins to fall, and the marginal increase is used first for durable goods (clothing, housing, cars) and then for luxury goods, recreation, and the like. Thus, a third sector, namely personal service, begins to grow: restaurants, hotels, car services, travel, entertainment, sports, when the horizon of people develops and new desires and tastes develop. The development of cyberspace has influenced life[4][5].

The development of cyberspace has influenced social life at various levels. The existence of cyberspace has not only created a very fundamental social change, even by various thinkers said to have led to the extreme conditions of 'social death' (death of the social). Apart from this extreme thinking, the influence of cyberspace on social life is at least visible at three levels: individual, inter-individual and community level[6][7].

Cyberspace is a space without authority, so that everyone can cross the boundaries that he should not cross (boundaries of desire, fantasy, pleasure, passion). However, that does not mean there is no power (power) and hegemony (hegemony) in it. Even though it is a free space of authority, there are still parties who want power, domination and hegemony within it, and other parties that are controlled, controlled and dominated[8].

Millennials will carve out fresh concepts of public cyberspace and use information to empower groups rather than individuals[9]. As the first generation to grow up with mobile digital technology, Millennials expect nonstop interaction with their peers in forms that would have been unimaginable to prior generations of young adults. They will develop new standards for social networking, identifying a clear range of acceptable online attitudes and behaviours[10] [11]

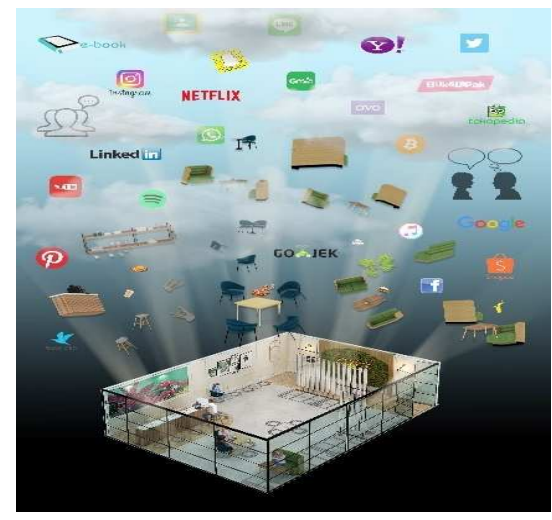




\section{CONCLUSION}

The rapid progress of information technology has resulted in changes in social interactions that occur in real space in millennial generations, this is due to the ease of millennial generation in carrying out their daily activities so that many facilities in real space have been largely replaced in cyberspace through applications. applications that develop such as to find information on various things through Google, recreation through Youtube, shopping through in-line shopping, service delivery order needs through Grab, go-clean goat service, go-food, and so forth.

Real space which has largely been replaced by virtual space due to the advancement of technology has a different behavioral impact. When Millennials utilize real space when conducting social interactions, all senses will be used directly (talking, staring, listening, feeling, smelling, moving according to the needs of the activity being carried out), cognitive and psychomotor aspects remain balanced. Whereas when millennial generation utilizes virtual space as its activity, only a portion of the five senses that are actively moving (vision and hearing) cognitive aspects are very dominant compared to their psychomotor).

\section{REFERENCES}

[1] Yasraf Amir Piliang. "Masyarakat Informasi dan Digital"; Teknologi Informasi dan Perubahan Sosial”. Jurnal Sosioteknologi, Vol 27 (11), Desember 2012.

[2] Alvara Research Center, The Urban Middlle-Class Millennials, 2017

[3] Christopher Hight, Architectural Principles in the Age of Cybernetics, Taylor \& Francis e-library, New York 2008.

[4] John W. Creswell, Qualitative Inquiry \& Research Design: Choosing five among Approaches, SAGE Publication. 2013.

[5] James Lull. Culture in Communication Age. London and NewYork. 2001.

[6] Howe, N., \& Strauss, W; "The Next 20 Years: How Customer and Workforce Attitudes Will Evolve" New York: Vintage. 2007.

[7] Frank Webster. The Information Society Reader; by Routledge. 2004.

[8] Wellman, B. 'An electronic group is virtually a social network'. In S. Kiesler (ed.), Cultures ofthe Internet. Mahwah, NJ: Lawrence Erlbaum. 1997.

[9] Robins, K. 'Cyberspace and the world we live in'. In M. Featherstone (ed.), Cyberspace/Cyberbodies/Cyberpunk. London: Sage Publications. 1995.

[10] Henri Lefebvre. Space, Difference, Everyday Life; Routledge. 2008.

[11] K. Saddhono, I. K. Sudarsana, and A. Iskandar, "Implementation of Indonesian Language The learning Based on Information and Communication Technology in Improving Senior High School Students' Achievement in Surakarta," in Journal of Physics: Conference Series, 2019, vol. 1254, no. 1, p. 12059. 